\title{
Campaña vacunal frente a Gripe A. Opiniones sobre la inmunización entre el Colectivo Médico
}

\author{
Candelaria Ayuso Raya ${ }^{a}$, Javier Lucas Pérez-Romeroa, \\ Inmaculada Martínez Pardoa , Francisco Escobar Rabadán ${ }^{b}$
}

\begin{abstract}
a Residentes de Medicina Familiar y Comunitaria. Unidad Docente de Albacete.

\author{
${ }^{\mathrm{b}}$ Médico de Familia. Centro \\ de Salud Universitario \\ Zona IV de Albacete. \\ Profesor Asociado de \\ la Facultad de Medicina \\ de Castila- La Mancha.
}

Correspondencia: Candelaria Ayuso Raya, Centro de Salud Zona IV, c/ Seminario $n^{\circ} 4$, 02006 - Albacete, España. Telf.: 967510094 , correo electrónico: candeayuso@hotmail.com.
\end{abstract}

Recibido el 31 de marzo de 2010

Aceptado para su publicación el 6 de junio de 2010.

\section{RESUMEN}

Objetivo. Conocer la proporción de profesionales sanitarios vacunados frente a gripe estacional y gripe A, así como las motivaciones para hacerlo.

Diseño del estudio. Estudio observacional, descriptivo, transversal.

Emplazamiento. Atención primaria y servicio de neumología hospitalario.

Participantes. 138 facultativos, de los que 88 eran médicos de familia, 30 residentes de esta especialidad, 9 pediatras y 11 neumólogos.

Resultados. Se había vacunado frente a gripe estacional el 59,4\% (IC95\%: 50,8-68,0) y frente a gripe A el 31,2\% (IC95\%: 23,1-39,3). El 15,2\% consideraba que esta vacuna debería ser obligatoria. En cuanto a las razones para no vacunarse, 16,5\% mostraba miedo a posibles efectos secundarios, $37 \%$ consideraba que no había suficientes ensayos clínicos, $31,2 \%$ manifestaba que la información era poco clara, 9,4\% pensaba que la cepa podría haber mutado, y un $15,9 \%$ no se consideraba especial transmisor. Un $67,4 \%$ de los médicos pensaba que las autoridades sanitarias recomiendan la vacuna a los profesionales para evitar el contagio a los pacientes, aunque para un $63,8 \%$ evitaría el absentismo laboral.

Conclusión. El seguimiento de la vacunación frente a la gripe A ha sido mucho menor que frente a la gripe estacional. Entre otros factores habría que atribuirlo a la desconfianza que la vacuna generaba entre los profesionales sanitarios.

Palabras clave. Vacunas, Gripe A, Profesionales Sanitarios.

\section{ABSTRACT}

Swine flu vaccination campaign. Opinion on immunization among doctors.

Objective. To determine the proportion of healthcare professionals who were vaccinated against Swine flu, and their reasons for doing so.

Design. Cross-sectional, descriptive observational study.

Setting. Primary care and hospital pneumology department

Participants. A total of 138 doctors of whom 88 were family doctors, 30 house physicians in this speciality, 9 paediatricians and 11 pneumologists.

Results. A total of $59.4 \%$ (95\% Cl: $50.8-68.0)$ of doctors had been vaccinated against seasonal flu and $31.2 \%$ (95\% Cl: $23.1-39.3)$ against swine flu. $15.2 \%$ considered that this vaccine should be compulsory. As regards reasons for not being vaccinated, $16.5 \%$ were afraid of possible side effects, $37 \%$ considered there were not enough clinical trials, $31.2 \%$ stated that the information was not clear enough, $9.4 \%$ thought the strain could have mutated and $15.9 \%$ did not consider themselves likely to transmit the virus. $67.4 \%$ of the doctors thought that the health authorities recommended the vaccine to health professionals in order to avoid infecting the patients, although $63.8 \%$ thought that it would avoid absenteeism.

Conclusion. Vaccination against Swine flu was much less than against seasonal flu. Amongst other factors, this could be attributed to the lack of confidence in the vaccine amongst the health professionals.

Key words. Vaccines, Influenza A, Health care professionals. 


\section{INTRODUCCIÓN}

En marzo de 2009 se detectaron en México varios brotes de gripe causados por la aparición de la infección por el virus A (H1N1) de origen porcino. Unas semanas más tarde, en San Diego (California, Estados Unidos), se observó también la presencia de gripe debida al mismo virus. El 11 de Junio de 2009 , después de que este virus se hubiera extendido a más de 70 países y afectado a más de 30.000 personas, la Organización Mundial de la Salud (OMS) declaró el grado de pandemia en fase 6 y comenzó la organización de una respuesta global a esta situación. En septiembre de 2009, el virus se extendió a 191 países, se declararon más de 300.000 casos confirmados, de ellos, 130.000 en América y 53.000 en la región europea, y 3.917 muertes. El número real de casos, no obstante, supera ampliamente estas cifras, puesto que sólo en un número limitado de pacientes se ha dispuesto de diagnóstico de laboratorio.

Se estima que en Europa la tasa de ataque alcanzó un 20\%. La tasa de hospitalización estimada en Europa (ECDC) ha supuesto en la población joven un $0,2 \%$ de los menores de 15 años, un $35 \%$ en edades comprendidas entre los 5-44 años y un 3\% en mayores de 65 años. Entre el 20-25\% ingresaron en $\mathrm{UCl}$, una cifra 15 veces mayor que en gripe estacional, y como dato a resaltar el $70-80 \%$ de los pacientes pertenecían a grupos de riesgo. La tasa de mortalidad en España ha supuesto el 0,014\% de los infectados, letalidad similar o inferior a la gripe estacional, resaltando que los casos más graves y letales se han producido en adultos jóvenes (70\% en edades comprendidas entre los 25-54 años) y más del $80 \%$ de los fallecidos pertenecían a grupos de riesgo, presentando complicaciones neumónicas consistentes en neumonía vírica o bacteriana grave rápidamente progresiva ${ }^{1}$. El nuevo virus, denominado H1N1 2009 y del cual se ha establecido como cepa de referencia la llamada A/California/04/2009, presenta en su genoma 6 fragmentos (PB2, PB1, PA, HA, NP y NS) similares a los hallados previamente en virus circulantes en la población porcina de Estados Unidos, denominados triple recombinantes. Antigénicamente, el H1N1 2009 es homogéneo y muy similar al virus porcino H1N1 clásico y a los virus triples recombinantes porcinos circulantes en Estados Unidos en los últimos 10 años ${ }^{2}$.

Ante esta situación de pandemia se pusieron en marcha una serie de planes, guías, recomendaciones y protocolos de actuación, teniendo en cuenta las recomendaciones de la OMS, así como con las distintas directrices de la Comisión Europea y del Ministerio de Sanidad y política social.

Mediatizados y marcados por la incertidumbre científica ante la nueva enfermedad, y ante la obli- gación de asumir las recomendaciones para el correcto abordaje clínico de los pacientes sin una sólida evidencia científica, se genera en muchos de los profesionales una reacción de desconfianza ante la efectividad de las medidas terapéuticas y preventivas disponibles contra la infección. Nuestro estudio, por tanto, pretende analizar qué variables, conocimientos y actitudes surgen hacia la vacunación en médicos de Atención Primaria y en un sector de médicos hospitalarios.

\section{MATERIAL Y MÉTODO}

Se trata de un estudio observacional, descriptivo y transversal en el que se incluyeron 138 médicos, de los que 88 eran médicos de familia, 30 residentes de esta especialidad, 9 pediatras y 11 neumólogos.

Por medio de un cuestionario diseñado ad hoc, autoadministrable y anónimo, elaborado y distribuido por el equipo investigador, se recogieron las variables categoría profesional, preguntas sobre si se habían vacunado frente a gripe estacional y gripe $\mathrm{A}$, la opinión sobre la campaña de vacunación planteada desde el Ministerio de Sanidad y Consumo, opinión sobre la obligatoriedad en profesionales sanitarios, así como las motivaciones que pudieran justificar sus decisiones. Las preguntas eran cerradas, y la mayoría se confeccionaron como variables dicotómicas, con respuestas "si" o "no". Para conocer las razones por las que rechazaron la vacunación, se incluyeron como opciones de respuesta: no haberse vacunado todavía por enfermedad, se vacunará en los próximos días, miedo a posibles efectos adversos, no hay suficientes ensayos clínicos de la vacuna, es poco eficaz, la cepa no se corresponde con la actual ya que ha mutado, la vacuna ha llegado demasiado tarde, la información acerca de la vacuna es poco clara y no considerar que tenga una mayor probabilidad de transmitir la enfermedad que en la población general.

El estudio fue realizado en los Centros de Salud Zonas I, II, III, IV, VA, VB, VI, VII y VIII de Albacete, así como en los de Casas Ibáñez y Alcadozo, y se distribuyó el cuestionario también entre los residentes de Medicina de Familia y Comunitaria de tercer y cuarto año de la Unidad Docente de Albacete-Hellín y en el Servicio de Neumología del Complejo Hospitalario Universitario de Albacete.

Se distribuyeron las encuestas entre el personal sanitario el día 30 de Noviembre de 2009, dos semanas después del comienzo de la campaña de vacunación frente a gripe $A$, y se recogieron una semana después de ser entregadas en un sobre en el que cada profesional la depositaba de forma anónima tras su cumplimentación. 
Se realizó el análisis descriptivo de cada una de las variables con sus respectivos intervalos de confianza (IC) del 95\%. Posteriormente se buscaron diferencias significativas, agrupándolas mediante tablas de contingencia con la prueba estadística de la chi-cuadrado para explicar la asociación. Se empleó el programa SPSS 12.0.

\section{RESULTADOS}

Al analizar el porcentaje de vacunados frente a la gripe estacional, se observó que era de un 59,4\% (IC95\%: 50,8-68,0), habiéndose vacunado un 58,8 $\%$ de los médicos de Atención Primaria, un 55,6 \% de los Pediatras de Centro de Salud, un $70 \%$ de los Residentes de Medicina de Familia y Comunitaria (MFyC) y un 54,5\% de los Neumólogos.

En cuanto a la vacunación frente a la gripe $A$, afirmaron haberse vacunado un 31,2\% (IC95\%: 23,139,3 ) del total de los médicos encuestados. El 28,2 $\%$ correspondía a Médicos de Atención Primaria, porcentaje similar al de Residentes (30 \%). El colectivo que se había vacunado en un mayor porcentaje era el de Neumólogos ( $54,5 \%$ ), seguido del de Pediatras de Atención Primaria (44,4\%). Solo el $15,2 \%$ consideraba que esta vacuna debería ser obligatoria, siendo los Residentes de MFyC los que se oponían de manera más rotunda $(93,3 \%)$, seguidos de los Médicos de Atención Primaria $(88,2 \%)$ y los Pediatras $(77,8 \%)$.

En cuanto a las razones para no vacunarse frente a Gripe A, un $16,5 \%$ mostraba miedo a posibles efectos secundarios, el $37 \%$ consideraba que no había suficientes ensayos clínicos, el 31,2\% manifestaba que la información era poco clara, el 9,4\% pensaba que la cepa podría haber mutado, y un $15,9 \%$ no se consideraba especial transmisor (tabla 1).

Un $67,4 \%$ de los médicos pensaba que las autoridades sanitarias recomiendan la vacuna a los profesionales para evitar el contagio a los pacientes, aunque para un $63,8 \%$ evitaría el absentismo laboral (tabla 2).

\section{DISCUSIÓN}

El Consejo Interterritorial de Salud del Sistema Nacional de Salud, en la reunión celebrada el 22 de

\begin{tabular}{|c|c|c|c|c|c|}
\hline & $\begin{array}{l}\text { Médicos de } \\
\text { Atención } \\
\text { Primaria }\end{array}$ & $\begin{array}{l}\text { Pediatras de } \\
\text { Atención } \\
\text { Primaria }\end{array}$ & $\begin{array}{c}\text { Residentes } \\
\text { de MFyC } \\
\text { (R3 y R4) }\end{array}$ & Neumólogos & Total \\
\hline $\begin{array}{l}\text { No se ha vacunado todavía } \\
\text { por enfermedad }\end{array}$ & $2,4 \%$ & $11,1 \%$ & $3,3 \%$ & $9,1 \%$ & $3,6 \%$ \\
\hline Se vacunará en los próximos días & $3,5 \%$ & $11,1 \%$ & $10 \%$ & $18,2 \%$ & $6,5 \%$ \\
\hline $\begin{array}{l}\text { Miedo a posibles efectos } \\
\text { secundarios graves }\end{array}$ & $11,8 \%$ & $11,1 \%$ & $36,7 \%$ & $9,1 \%$ & $16,5 \%$ \\
\hline $\begin{array}{l}\text { No hay suficientes ensayos } \\
\text { clínicos de la vacuna }\end{array}$ & $41,2 \%$ & $22,2 \%$ & $43,3 \%$ & $0 \%$ & $37 \%$ \\
\hline Es poco eficaz & $3,5 \%$ & $0 \%$ & $13,3 \%$ & $0 \%$ & $5,1 \%$ \\
\hline $\begin{array}{l}\text { La cepa de la vacuna no se } \\
\text { corresponde con la actual ya } \\
\text { que ha mutado }\end{array}$ & $8,2 \%$ & $0 \%$ & $16,7 \%$ & $9,1 \%$ & $9,4 \%$ \\
\hline La vacuna ha llegado demasiado tarde & $7,1 \%$ & $11,1 \%$ & $3,3 \%$ & $0 \%$ & $5,8 \%$ \\
\hline $\begin{array}{l}\text { La información acerca de la vacuna } \\
\text { es poco clara }\end{array}$ & $35,4 \%$ & $11,1 \%$ & $30 \%$ & $9,1 \%$ & $31,2 \%$ \\
\hline $\begin{array}{l}\text { No considera que tenga una } \\
\text { probabilidad mayor de transmitir la } \\
\text { enfermedad que la población general }\end{array}$ & $22,4 \%$ & $11,1 \%$ & $3,3 \%$ & $0 \%$ & $15,9 \%$ \\
\hline
\end{tabular}

Tabla 1. Proporción de médicos que justificaba las diferentes razones planteadas para no vacunarse frente a Gripe A.

\begin{tabular}{l|ccccc}
\hline & $\begin{array}{c}\text { Médicos de } \\
\text { Atención } \\
\text { Primaria }\end{array}$ & $\begin{array}{c}\text { Pediatras de } \\
\text { Atención } \\
\text { Primaria }\end{array}$ & $\begin{array}{c}\text { Residentes } \\
\text { de MFyC } \\
\text { (R3 y R4) }\end{array}$ & Neumólogos & Total \\
\hline $\begin{array}{l}\text { Evitar absentismo laboral entre el } \\
\text { personal sanitario }\end{array}$ & $65,9 \%$ & $88,9 \%$ & $60 \%$ & $54,5 \%$ & $63,8 \%$ \\
$\begin{array}{l}\text { Evitar riesgo de contagio entre el } \\
\text { personal sanitario }\end{array}$ & $38,8 \%$ & $44,4 \%$ & $56,7 \%$ & $45,5 \%$ & $42,8 \%$ \\
$\begin{array}{l}\text { Evitar el contagio posterior } \\
\text { a pacientes }\end{array}$ & $65,9 \%$ & $88,9 \%$ & $70 \%$ & $63,6 \%$ & $67,4 \%$ \\
\hline
\end{tabular}

Tabla 2. Proporción de médicos que apoyaba las diferentes razones por las que las autoridades sanitarias recomendarían la vacuna a los profesionales. 
octubre de 2009, acordó que la campaña de vacunación frente a la gripe pandémica $\mathrm{A} / \mathrm{H} 1 \mathrm{~N} 1$ se iniciaría el 16 de Noviembre de 2009 en todas las Comunidades Autónomas, siguiendo las recomendaciones oficiales. Desde el comienzo de la vacunación se puso en marcha el Plan de Farmacovigilancia de las vacunas pandémicas que incluía, entre otras acciones, un plan para la notificación, manejo y análisis de las sospechas de reacciones adversas comunicadas a través del Sistema Español de Farmacovigilancia de medicamentos de uso humano (SEFV-H) 1 .

Frente a la pandemia causada por H1N1 2009, una intervención esencial es la utilización de vacunas, con los objetivos de disminuir la morbilidad y la mortalidad, reducir la transmisión en el seno de la comunidad y proteger la integridad de los servicios sanitarios y las infraestructuras esenciales ${ }^{2,3}$. La vacunación de los colectivos de alto riesgo para la infección es, en estos momentos, la medida más eficaz para reducir la morbimortalidad ${ }^{3-5}$. El uso de la vacuna va encaminado a reducir el impacto de la infección y por tanto su indicación se realiza en función de los mismos criterios utilizados para la gripe estacional, recomendando la vacunación a aquellos grupos con mayor riesgo de complicaciones o que prestan servicios esenciales para la comunidad ${ }^{1,4}$.

La estrategia de vacunación ha sido recomendada por diferentes organismos internacionales, entre los que se encuentra el Comité de Seguridad sanitaria de la Unión Europea y el grupo de Expertos en Asesoramiento Estratégico sobre inmunización (SAGE) de la OMS. Dicho grupo, el 7 de julio de 2009 en su nota de orientación sobre la gripe pandémica (H1N1), recomendó, ante la previsible incapacidad de cumplir con todas las necesidades de vacunación al inicio de la campaña, adoptar un método gradual para vacunar a determinados grupos. Así, como primera medida prioritaria para proteger la infraestructura sanitaria esencial, recomendó vacunar al personal sanitario que presta asistencia sanitaria. Además, propuso los siguientes grupos: embarazadas, niños mayores de 6 meses de edad que produzcan algún trastorno crónico, adultos jóvenes sanos de 15 a 49 años de edad, niños sanos, adultos sanos de 50 a 54 años y adultos sanos a partir de los 65 años ${ }^{1}$.

No hemos encontrado la existencia en la literatura médica de otro estudio que analice los motivos de los trabajadores sanitarios para no vacunarse frente a gripe A. Creemos por tanto que nuestro trabajo aporta una perspectiva interesante en este tema. Somos conscientes del sesgo que implica la selección de una muestra de conveniencia, sin embargo optamos por esta estrategia por la posibilidad que nos ofrecía de conseguir de forma inmediata las respuestas de aquellos profesionales a los que teníamos fácil acceso. Por otra parte, supone una limitación de nuestro estudio el hecho de no haber incluido variables sociodemográficas fundamentales como edad y sexo, con el fin de preservar la confidencialidad de la encuesta al incluir centros de salud con pocos trabajadores.

Nuestros resultados confirman que la aceptación de la vacuna frente a gripe A por parte de los médicos es baja. Como motivos para no vacunarse consideraban en mayor porcentaje que la información acerca de la vacuna era poco clara y que no existían suficientes ensayos clínicos sobre la vacuna, opinión mayoritaria en Residentes de MFyC. Un porcentaje menor de los profesionales no se vacunó por miedo a posibles efectos secundarios graves y por considerar insuficientes los estudios sobre seguridad y eficacia post-autorización. Finalmente un porcentaje menor se sintieron desinformados y desconfiados, marcados por la incertidumbre científica ante la nueva enfermedad.

Rodríguez Coronado ${ }^{5}$, a través de un estudio transversal, describió los motivos referidos por los profesionales de atención primaria para rechazar la medida preventiva frente a gripe común. Al analizar los distintos motivos por estamentos, mientras que para los médicos la pereza o la dejadez ha sido el motivo fundamental, para el resto ha sido considerar que la gripe tiene baja frecuencia entre profesionales. Existe una alta resistencia a la vacunación entre el personal de los centros sanitarios. Los estudios publicados muestran unas tasas de vacunación bajas (entre el 5 y el $38 \%$ ) en el ámbito nacional e internacional, tanto en los centros de atención primaria como en hospitales. Diversos autores han descrito como variables predictoras para no vacunarse contra la gripe en el ámbito hospitalario: la edad más joven, no haberse vacunado en campañas anteriores, creer que la vacuna es ineficaz, haber tenido efectos secundarios, evitar medicación, confiar en las propias defensas del organismo y temor a efectos secundarios ${ }^{5-9}$, resultados extrapolables a las opiniones emitidas por nuestros profesionales encuestados.

La cobertura vacunal frente a gripe estacional muestra porcentajes de vacunación más altos. Las coberturas más elevadas en dichos estudios responden a la puesta en marcha de distintas estrategias $^{5}$. En nuestro estudio se vacunó frente a gripe estacional el 59,4\% (IC95\%: 50,8-68,0) y frente a gripe A el 31,2\% (IC95\%: 23,1-39,3).

Para la evaluación y autorización de las vacunas por parte de la EMEA se han seguido los mismos 
criterios técnicos de calidad, eficacia y seguridad con los que las Agencias de Medicamentos emiten la autorización nacional de cualquier medicamento. Se ha valorado la inmunogenicidad de la vacuna incluso en el escenario más desfavorable. A estas vacunas se les ha exigido demostrar su eficacia y seguridad con ensayos clínicos de forma similar a la estacional ${ }^{1}$.

Es necesario valorar en futuros estudios tanto los factores predictores de la vacunación en atención primaria, como qué intervenciones pueden mejorar los conocimientos y cambiar la actitud de los profesionales sanitarios para mejorar las tasas de vacunación de la gripe en los equipos de atención primaria y entre profesionales hospitalarios. A la luz de los presentes resultados, las estrategias deben ser diferentes en cada categoría profesional ${ }^{3}$. Parece justificado admitir que existe la necesidad de aumentar los conocimientos de los profesionales sanitarios sobre las vacunas. La administración sanitaria debe apoyar iniciativas de formación rigurosas que alcancen a todos los grupos profesionales y no confiar sólo en lo legislado, la emisión de protocolos, la edición de normas o la informatización de registros. Los profesionales de atención primaria, y especialmente las enfermeras y los pediatras, son el medio que vincula al usuario con el proceso vacunal, por lo que un bajo nivel de información puede empobrecerlo. Creemos que existe una falsa sensación de seguridad, un cierto grado de ambivalencia en el conocimiento del profesional que puede ser fuente de preocupación o desconfianza en una población cada vez más, no siempre mejor, informada ${ }^{10}$.

En definitiva, la experiencia vivida tras la campaña vacunal nos pone en jaque a los profesionales sanitarios. El principio de protección, la Medicina Basada en la Evidencia, el rigor científico deberían ser suficientes para el correcto abordaje clínico de nuestros pacientes. Dejemos que las creencias sub- jetivas, las falsas experiencias y las opiniones mediatizadas pierdan la próxima partida de ajedrez.

\section{BIBLIOGRAFÍA}

1. SemFYC [sede Web] Barcelona: Sociedad Española de Medicina de Familia y Comunitaria; 2009. Grupo de trabajo de Enfermedades Infecciosas de la SemFYC. Recomendaciones para profesionales sobre el manejo diagnóstico y terapéutico de infección por el virus de la influenza tipo A (H1N1) y la organización de la asistencia. Disponible en http://www.semfyc.es/es/biblioteca/virtual/detalle/ recomendaciones+influenza/. [Acceso 1 de Marzo de 2010].

2. Vidal J. Gripe, la amenaza permanente. Vacunas. 2009; 10:69-71.

3. Martín Martín S, Álvarez-Pasquín MJ, Sesmero-Lillo MA, Martínez-Alsina N, Gómez-Marco JJ. Recordatorios informáticos: una estrategia más de vacunación antigripal en pacientes menores de 56 años. Vacunas. 2006; 1:4-10.

4. Centers for Disease Control and Prevention (CDC) [sede Web] Atlanta: U.S. Department of Health \& Human Services; 2009. Fiore AE, Shay DK, Broder K, Iskander JK, Uveki TM, Mootrey $G$ et al. Prevention and control of seasonal influenza with vaccines. Recommendations of the Advisory Committee of Immunization Practices (ACIP), 2009. Disponible en: http://www.cdc.gov/mmwr/preview/mmwrhtlm/rr58e0724a1. htm. [Acceso 3 de Marzo de 2010].

5. Rodríguez Coronado V, García de Blas F, Reverte Asuero C, Herráiz Cristóbal R, Álvarez Villalba M. Motivos de los trabajadores sanitarios de atención primaria para no vacunarse contra la gripe. Vacunas. 2009; 10:37-41.

6. Ramón JM, Morchón S, Gené M, Font C, Ramírez M. Cobertura de la vacuna antigripal entre un colectivo de trabajadores sanitarios de un hospital de tercer nivel. Vacunas. 2003; 4:69-72.

7. Elorza JM, Campins M, Martínez X. Vacuna antigripal y personal sanitario: estrategias para aumentar las coberturas en un hospital de tercer nivel. Med Clin (Barc). 2002; 12:451-2.

8. Garcia de Codes A, Aráosla MP, Ramón de Juanes J, Sanz MI. Vacunación frente a la gripe en trabajadores de un hospital general. Estrategias para incrementar su cobertura. Med Clin (Barc). 2004; 123:532-4.

9. Harrison J, Abbott P. Vaccination against influenza: UK health care workers not on-message. Occup Med. 2002; 52:277-9.

10. Tulles J, Montagud Penadés E, García Paramio MP, Monfort García M, Conocimiento y actitud hacia la inmunización en profesionales sanitarios en atención primaria. Vacunas. 2009; 10:78-84. 